\title{
Tuberculosis de la vía biliar
}

\author{
Ángel Pierini, ${ }^{1}$ Leandro Pierini, ${ }^{2}$ Guillermo Ruiz, ${ }^{2}$ Alejandro García Hevia, ${ }^{3}$ \\ Rodrigo Meneghini ${ }^{3}$
}

\author{
${ }^{1}$ Jefe del Servicio (MAAC). Profesor Adjunto de Cirugía. Facultad de Ciencias Médicas, Universidad Nacional del Litoral (UNL). \\ ${ }^{2}$ Cirujano de Planta (MAAC). \\ ${ }^{3}$ Residente. \\ Servicio de Cirugía General Mixta, Hospital J. B. Iturraspe. Santa Fe, Argentina.
}

Acta Gastroenterol Latinoam 2020;50(1):65-68

Recibido: 18/06/2018 / Aceptado: 17/09/2018 / Publicado online: 23/03/2020 / https://doi.org/10.52787/wwmj5524

\section{Resumen}

La TBC biliar es una entidad poco frecuente y posiblemente subdiagnosticada, por lo que es un desafio diagnóstico y terapéutico en la actualidad, debido al aumento de su incidencia en la población. No existen características patognomónicas del diagnóstico por imagen de la TBC biliar; por este motivo, se obtiene mediante el estudio histopatológico de la pieza. Presentamos el caso clínico de una paciente de sexo femenino de 29 años de edad que consulta por ictericia progresiva, coluria y prurito. Como único antecedente de jerarquía es veterinaria de grandes animales. La paciente es estudiada con laboratorio, ecografía y resonancia magnética, con sospecha de tumor de la vía biliar. Se decide la conducta quirúrgica con resección de vesicula $y$ via biliar $y$ anastomosis biliodigestiva con anatomia patológica y PCR (proteina $C$ reactiva) que informa $T B C$ de la vía biliar.

Palabras claves. Tuberculosis, vía biliar, colestasis, ictericia, diagnóstico, tratamiento.

Correspondencia: Rodrigo Meneghini

Bv. Pellegrini 3551 (3000). Servicio de Cirugía General, Hospital J. B. Iturraspe. Santa Fe, Argentina

Correo electrónico: roymeneghini@hotmail.com

\section{Tuberculosis of the Bile Duct Summary}

Biliary TBC is a rare entity, possibly underdiagnosed and is, therefore, a diagnostic and therapeutic challenge today, due to the increase in its incidence in the population. There are no pathognomonic characteristics of imaging diagnosis of biliary TBC; for this reason, it is obtained by histopathological study of the piece. We present the clinical case of a 29-year-old female patient who consults for progressive jaundice, choluria, and pruritus. As the only antecedent of hierarchy, she is the veterinary of large animals. The patient is studied with laboratory, ultrasound and magnetic resonance, with suspected bile duct tumors. Surgical behavior is decided with gallbladder and bile duct resection and biliodigestive anastomosis with pathological anatomy and PCR (C-reactive protein) that reports TBC of the bile duct.

Keywords. Tuberculosis, biliary, cholestasis, jaundice, diagnosis, treatment.

\section{Introducción}

La tuberculosis de la vía biliar es un desafío diagnóstico.

La tuberculosis (TBC) está lejos de ser una enfermedad en remisión. Si bien es más frecuente en los países 
en vías de desarrollo, en este último tiempo ha aumentado en países industrializados debido, en parte, a la migración poblacional y otros factores causales, tales como las cepas de Mycobacterium tuberculosis resistentes y a un número creciente de pacientes inmunosuprimidos y diabéticos. ${ }^{1-8}$

La afectación del hígado y del sistema biliar se debe principalmente a la tuberculosis pulmonar miliar, aunque el sistema gastrointestinal también puede actuar como fuente del bacilo. ${ }^{2}$

Se cree que la tuberculosis biliar se produce por tres vías: más comúnmente como infección descendente de los conductos porta a los conductos biliares, de linfadenitis periportal tuberculosa, y de infección ascendente a través de la ampolla de Váter. ${ }^{3}$

La principal vía de propagación del bacilo al hígado es hematógena, desde los pulmones a través de la arteria hepática. ${ }^{4,7}$

Los síntomas y signos en la tuberculosis biliar pueden deberse a una tuberculosis primaria o secundaria que afecta al tracto biliar y causa: estenosis; colangitis por rotura de granulomas caseificantes en los conductos biliares; compresión extrínseca periportal, y pericoledoco por adenitis tuberculosa. ${ }^{?}$

\section{Caso}

Paciente femenino de 29 años de edad que consulta por cuadro de 7 días de evolución de comienzo insidioso y evolución progresiva, caracterizado por ictericia, coluria y prurito.

Laboratorio: GR: $4.730 .000 / \mathrm{mm}^{3}$; GB: $5.100 / \mathrm{mm}^{3}$; Hto: 43\%; Hb: 13,5 gr/\%; VSG: $30 \mathrm{~mm}$ TP: $5 \mathrm{~min}$.

Bilirrubina total: $49,2 \mathrm{mg} / \mathrm{L}$; Bilirrubina directa: 15,6 mg/L; Bilirrubina indirecta: 33,6 mg/L; GOT: $88 \mathrm{U} / \mathrm{L}$; GPT: $168 \mathrm{U} / \mathrm{L} ;$ FAL: $580 \mathrm{U} / \mathrm{L}$.

Colinesterasa: 10,559 U/L.

Hepatitis B: no reactivo; sífilis (VDRL): no reactivo; virus de la inmunodeficiencia humana (VIH): no reactivo.

Marcadores tumorales: CA 19-9: $25 \mathrm{ng} / \mathrm{ml}$ y CEA: $3 \mathrm{ng} / \mathrm{ml}$.

En ecografía de abdomen se observó hígado de forma, tamaño, contornos y ecoestructura conservados, sin imágenes focales. Vía biliar intrahepática dilatada. Hepatocolédoco de 11,2mm. Vesícula distendida, de paredes finas, alitiasica. Páncreas sin particularidades (Figura 1).

Se completó estudio con colangiorresonancia, que informó marcada dilatación de la vía biliar intra y extra

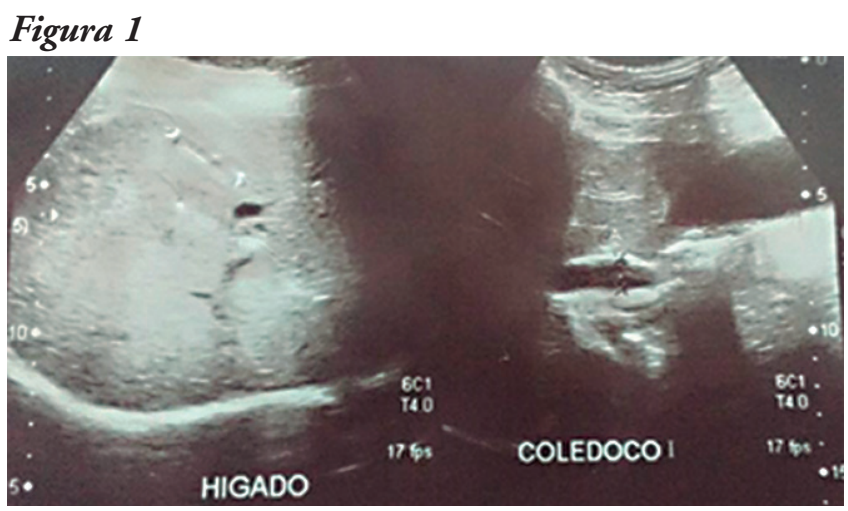

hepática proximal, identificándose hacia vía biliar intrahepática sutiles áreas de menor distensibilidad, con configuración de tipo arrosariada, frecuente en colangitis. Colédoco proximal de $10 \mathrm{~mm}$. En proyección del colédoco medio se observó sobre su cara dorsal y hacia el hilio hepático formación de 2,9 x 2,6 cm de contornos finamente lobulados, hipoteintensa en T1, levemente hiperintensas en T2, y que luego de la inyección de contraste endovenoso presentó refuerzo periférico así como también sus septos internos (Figura 2).

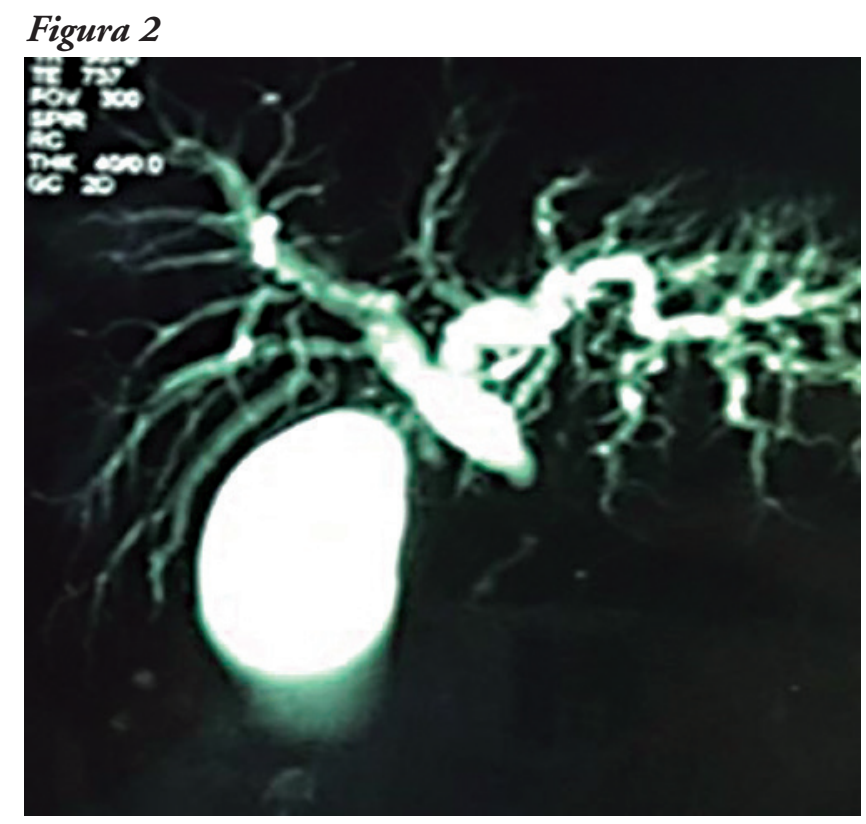

Ante la sospecha de tumor de vía biliar se realizó tomografía axial computada (TAC) de tórax, abdomen y pelvis donde no se visualizaron lesiones a distancia.

Se decidió el acceso quirúrgico mediante laparotomía subcostal derecha. Se realizó colecistectomía más resección de la vía biliar proximal más linfadenectomia del pedículo hepático más hepático yeyuno anastomosis en Y de Roux (Figura 3 y 4). 


\section{Figura 3}

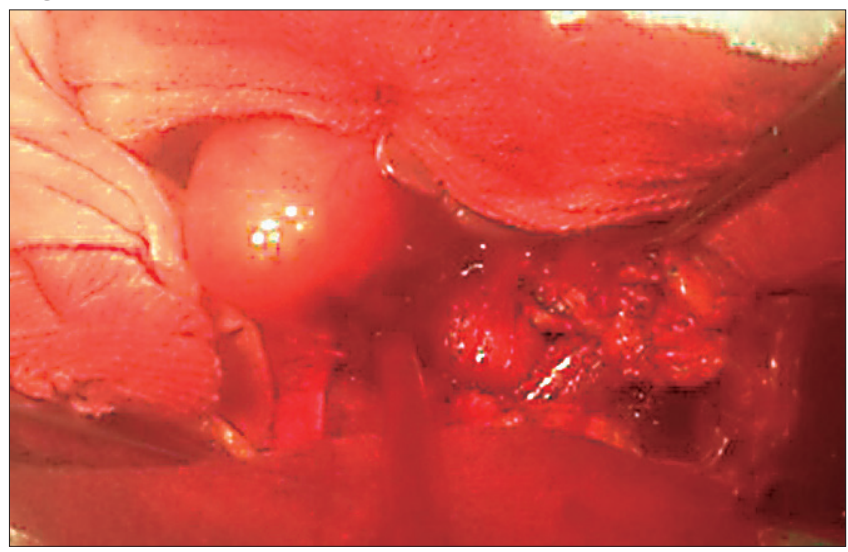

\section{Figura 4}

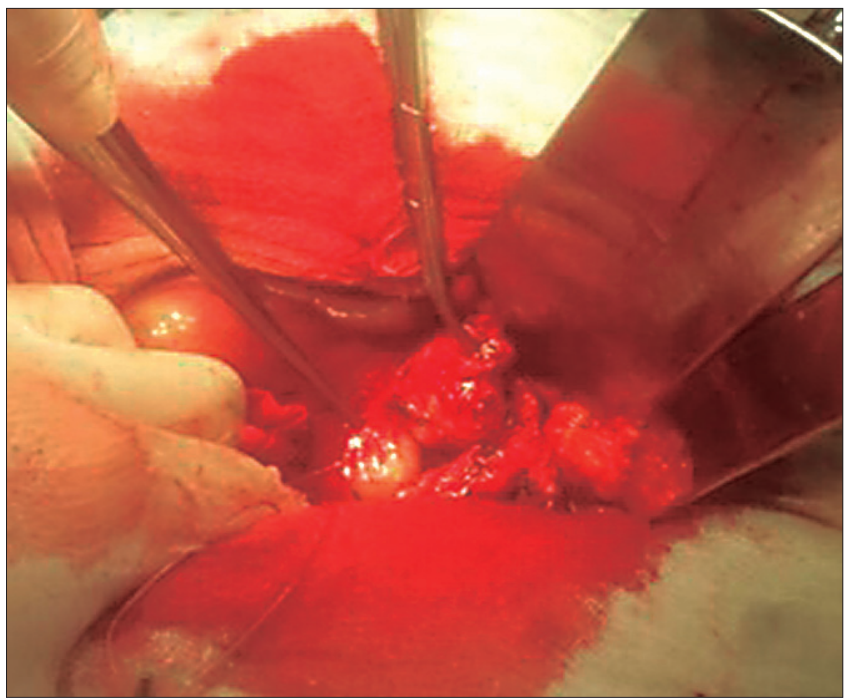

La anatomía patológica informó proceso granulomatoso necrotizante en conducto cístico y en vía biliar con colecistitis crónica y ganglios linfáticos reactivos. El examen microscópico mostró un proceso inflamatorio crónico granulomatoso con necrosis caseiforme central e histiocitos células gigantes de cuerpo extraño y presencia de linfocitos. La coloración de Fite Faraco es negativa para BAAR. Ante estos resultados se decidió realizar un estudio microbiológico, y se obtuvo una reacción en cadena de polimerasa (PCR) para Mycobacterium tuberculosis positiva, a pesar de una tinción Ziehl-Neelsen y cultivo de Lowenstein negativos. Se comprobó mediante radiografía simple de tórax y TAC torácica la ausencia de afectación pulmonar y ganglionar torácica.

La evolución fue satisfactoria y la paciente recibió el alta al $7^{\circ}$ día del postoperatorio. Posteriormente completó tratamiento antituberculoso con isoniacida, rifampicina y piracinamida durante seis meses (Figura 5).
Figura 5. Corte histológico representativo que exhibe una formación nodular constituida por un centro necrótico caseoso circunscripto por numerosos elementos linfoides y células epitelioides que se disponen en empalizada. Proceso inflamatorio crónico granulomatoso vinculable a TBC de la vía biliar.

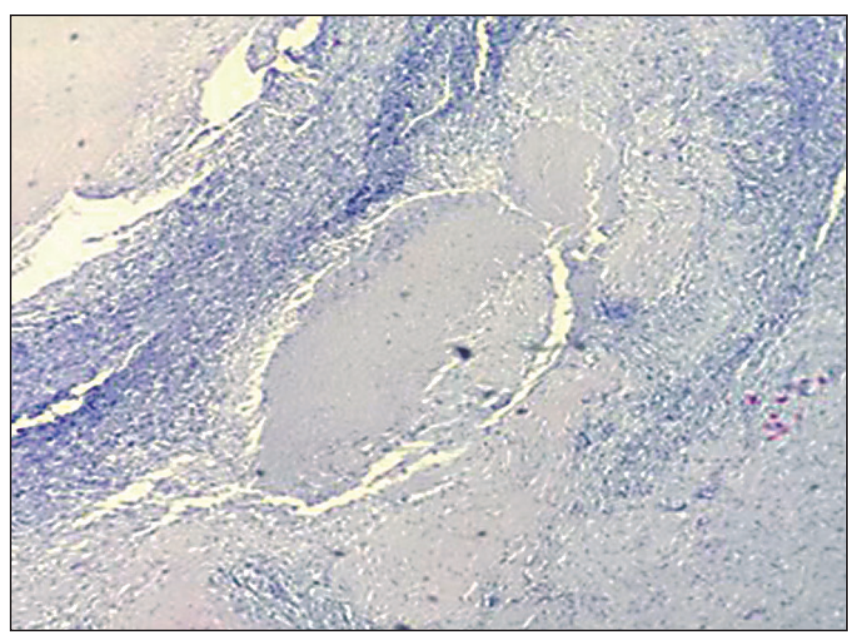

\section{Discusión}

La afectación de la TB biliar puede presentar hallazgos de imagen confusos y hacer que el diagnóstico sea difícil. Los signos y síntomas atribuibles a la tuberculosis del conducto biliar no son exclusivos. ${ }^{5,8}$

Las pruebas complementarias suelen ser inespecíficas, presentando anemia y aumento de la velocidad de sedimentación globular, que junto con el bajo nivel de sospecha clínica favorece que el diagnóstico se realice frecuentemente con el estudio histológico en el postoperatorio. ${ }^{6}$ Además de familiarizarse con los hallazgos de imágenes comunes, la historia clínica, los datos demográficos del paciente y su estado inmune también deben considerarse para alcanzar un diagnóstico correcto. El ultrasonido es generalmente la primera modalidad utilizada y puede ser útil para detectar obstrucción biliar, detección de lesiones hepáticas focales y ascitis. ${ }^{10}$ La tomografía de tórax y abdomen puede proporcionar signos para el diagnóstico tanto pulmonar como abdominal. La resonancia magnética, como en nuestro caso, permite una mejor identificación de las lesiones en vías biliares y su repercusión hepática y pancreática. ${ }^{11}$

No obstante, puesto que la actitud terapéutica es muy diferente, un diagnóstico correcto es de gran importancia para evitar cirugías innecesarias de elevada morbimortalidad. Para ello, es fundamental la obtención de biopsias de la lesión mediante punción guiada por ecoendoscopiapía para efectuar un estudio microbiológico y citológico. La presencia de granulomas ca- 
seosos en la citología es altamente sospechosa de TBC, en cuyo caso para la confirmación microbiológica se requiere una tinción Ziehl-Neelsen y/o cultivo positivos. ${ }^{12}$ No obstante, dado que las formas extrapulmonares de TBC son paucibacilares, la rentabilidad diagnóstica de estas técnicas puede ser baja y depende de la calidad de la muestra obtenida. Por ello, ante la sospecha de TBC y resultados negativos de las técnicas microbiológicas anteriores, podemos diagnosticar la TBC frente a resultados positivos de otros métodos más rápidos, como el adenosina deaminasa (ADA), interferón gamma (INF-g) y reacción en cadena de polimerasa (PCR) del bacilo tuberculoso, como en nuestro caso. Sin embargo, a pesar de la variedad disponible de técnicas diagnósticas, en caso de resultados no concluyentes de biopsias por punción-aspiración con aguja fina (PAAF), puede ser necesario recurrir a la cirugía para alcanzar un diagnóstico, como en nuestro caso. ${ }^{12,13}$

En nuestra paciente, debido al diagnóstico presuntivo de tumor de vía biliar y a la destrucción coledociana hallada en la cirugía, se realizó resección de vía biliar media con anastomosis con asa yeyunal en Y de Roux.

\section{Conclusión}

Se presenta un cuadro de colestasis secundario a proceso obstructivo con la sospecha clínica de tumor de vía biliar principal y la confirmación a posteriori de tratarse de un caso de tuberculosis de esa vía.

Se repasan estudios por imágenes (ecografía, tomografía, resonancia y ecoendoscopía), estudio histopatológico de la pieza, cultivo y PCR.

La terapéutica realizada fue la cirugía resectiva del sector comprometido de la vía billar y el posterior tratamiento médico con tres drogas, con buena evolución de la paciente.

Debido a que la presentación clínica de la TBC es vaga e insidiosa, el diagnóstico a menudo se retrasa. La sospecha clínica es la clave para el diagnóstico temprano y la pronta gestión, así como la prevención de la diseminación de la enfermedad. Los hallazgos de la imagen hepática y de la vía biliar pueden simular los de enfermedades neoplásicas e infecciosas más comunes. Teniendo en cuenta la dificultad de cultivar bacilos de M. tuberculosis, las imágenes pueden desempeñar un papel crucial para el diagnóstico, la orientación del tratamiento y el seguimiento de estos pacientes.

\section{Aviso de derechos de autor}

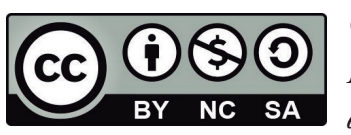

(C) 2021 Acta Gastroenterológica Latinoamericana. Este es un articulo de acceso abierto publicado bajo los términos de la Licencia Creative Commons Attribution (CC BY-NC-SA 4.0), la cual permite el uso, la distribución y la reproducción de forma no comercial, siempre que se cite al autor y la fuente original.

Cite este artículo como: Pierini A, Pierini L, Ruiz G y col. Tuberculosis de la vía biliar. Acta Gastroenterol Latinoam. 2020;50(1):65-8. https://doi.org/10.52787/wwmj5524

\section{Referencias}

1. Daniel TM. The history of tuberculosis: past, present and challenges for the future. In: Schaaf S, Zumla A, eds. Tuberculosis: a comprehensive clinical reference. Philadelphia, PA: Saunders 2009: 1-7.

2. Kumar V, Pandey D. Isolated hepatosplenic tuberculosis. Hepatobiliary Pancreat Dis Int 2008; 7: 328-330.

3. Álvarez SZ, Carpio R. Hepatobiliary tuberculosis. Dig Dis Sci 1983; 28: 193-200.

4. Álvarez SZ. Hepatobiliary tuberculosis. J Gastroenterol Hepatol 1998; 13: 833-839.

5. Govindasamy M, Srinivasan T, Varma V, Mehta N, Yadav A, Kumaran V, Nundy S. Biliary tract tuberculosis - a diagnostic dilemma. J Gastrointest Surg 2011; 15: 2172-2177.

6. Xu XF, Yu RS, Qiu LL, Shen J, Dong F, Chen Y. Gallbladder tuberculosis: CT findings with histopathologic correlation Korean J Radiol 2011; 12: 196-202.

7. Terry RB, Gunnar RM. Primary military tuberculosis of the liver. JAMA 1957; 164: 150-157.

8. Stemmerman M. Bile duct tuberculosis. Q Bull Sea View Hosp 1941; 6: 316-324.

9. Amarapurkar DN, Patel ND, Amarapurkar AD. Hepatobiliary tuberculosis in western India. Indian J Pathol Microbiol 2008; 51: 175-181.

10. Lamot JM. Guía de práctica clínica. Manejo de ictericia 25. O'Neill DE, Saunders MD. Ultrasonografía endoscópica obstructiva en el adulto, 2009. Neuquén: Enfermedades hospitalarias de la vesícula biliar. Gastroenterol Clin N Am Provincial Neuquén Dr. Castro Rendón, 2009.

11. Williams EJ, Green J, Beckingham I, Parks R, Martin D, Lombard M. Guidelines on the management of common bile duct stones (CBDS). Gut 2008; 57: 1004-1021.

12. Chaudhary P, Bhadara U, Arora M, et al. Pancreatic tuberculosis. Indian J Surg 2015; 77 (6): 517-524.

13. Yamada R, Inoue H, Yoshizawa N, et al. Peripancreatic tuberculous lymphadenitis with biliary obstruction diagnosed by endoscopic ultrasound-guided fine needle aspiration biopsy. Intern Med 2016; 55: 919-923. 